\title{
TỔNG QUAN VỀ Độl CẤP CỨU TRONG THẢM HỌA CHÁY NỔ VÀ BỎNG HÀNG LOẠT (Phần I)
}

\author{
Nguyễn Như Lâm, Đoàn Chí Thanh, Nguyễn Tiến Dũng \\ Bệnh viện Bỏng Quốc gia Lê Hữu Trác
}

\section{TÓM TẮT}

Do có những đặc điểm phức tạp về cơ cấu nạn nhân, mức độ bỏng, đặc biệt là bỏng hô hấp, công tác đáp ứng y tế trong thảm họa cháy nổ và bỏng hàng loạt đòi hỏi sự có mặt nhanh chóng của lực lượng y tế có kinh nghiệm, nhất là các chuyên gia về bỏng nhằm đảm bảo công tác phân loại, xử lý cấp cứu và vận chuyển nạn nhân về đúng cơ sở điều trị.

Năm 2020, Tổ chức Y tế Thế giới đã thành lập nhóm chuyên gia kỹ thuật về bỏng để xây dựng hướng dẫn về đội cấp cứu bỏng đáp ứng với các tình huống thảm họa cháy nổ và bỏng hàng loạt. Theo đó, có hai loại tổ/đội cấp cứu về bỏng bao gồm đội phản ứng nhanh (BRRT - Burn rapid response team) và đội chuyên khoa bỏng ( BST - Burn specialist team).

Bài tổng quan này nhằm giới thiệu chức năng, nhiệm vụ, biên chế của các đội cấp cứu bỏng cũng như vai trò của công tác đào tạo, cơ chế hợp tác của các đội này trong khi thực hiện nhiệm vụ.

\section{SUMMARY,}

Due to complicated characteristics of patient category, burn severity, especially inhalation injury, medical response for fire and explosive disaster and mass burn injuries requires the rapid presence of experienced medical staff, especially burn specialists, to ensure proper triage, emergency treatment and transferring victims to appropriate health facilities.

In 2020, the World Health Organization established a technical expert group on burns to develop guidelines for burn emergency teams responding to mass-burn injuries. Accordingly, there are two types of burn emergency teams, including the burn rapid response team, abbreviated as BRRT and the burn specialist team, abbreviated as BST.

The content of this overview introduces the functions, duties and staffing of burn emergency teams as well as the role of training and cooperation mechanisms of these teams while performing their duties.

Chịu trách nhiệm: Nguyễn Như Lâm, Bệnh viện Bỏng Quốc gia Lê Hữu Trác

Email: lamnguyenau@yahoo.com

Ngày nhận bài: 14/7/2021; Ngày nhận xét: 10/8/2021, Ngày duyệt bài: 20/8/2021 


\section{1. ĐộI PHẢN ỨNG NHANH (BRRT)}

Đội phản ứng nhanh có vai trò quan trọng trong giai đoạn đầu của ứng phó với thảm họa bỏng nhằm hỗ trợ hệ thống y tế địa phương trong phân loại, đánh giá nạn nhân, cấp cứu và điều phối công tác vận chuyển nạn nhân đến các cơ sở y tế trong toàn quốc. Các đội phản ứng nhanh có thể là của khu vực hoặc của quốc gia, thông thuộc địa hình, nắm được tình hình y tế tại địa phương. Đội phản ứng nhanh có các nhiệm vụ chính gồm 1:

- Đánh giá tình hình

- Thực hành triển khai chuyên môn tại các cơ sở y tế tuyến đầu

- Phối kết hợp với các lực lượng y tế tại chỗ và trung tâm điều hành khẩn cấp y tế (Health Emergency Operation Center HEOC) trong việc vận chuyển nạn nhân, điều phối các nguồn lực và thông tin liên lạc.

Đội phản ứng nhanh thường mang tính cơ động do vậy sẽ không duy trì thời gian hoạt động lâu dài để bàn giao cho đội cấp cứu chuyên khoa. Trong trường hợp thảm họa có quy mô lớn có thể phải huy động cùng lúc nhiều đội phản ứng nhanh để đáp ưng tình hình.

\section{1. Đánh giá tình hình}

- Đánh giá nhanh tình trạng hiện tại, ước tính số lượng bệnh nhân.

- Đánh giá, kiểm tra toàn diện về nguồn lực sẵn có tại cơ sở y tế tiếp nhận đầu tiên và các cơ sở chuyên khoa bỏng nếu có.

\subsection{Thực hành triển khai chuyên môn}

- Hỗ trợ lực lượng y tế địa phương trong đánh giá nạn nhân, tái phân loại và tiếp tục chăm sóc bệnh nhân tại cơ sở y tế tiếp nhận đầu tiên.

- Hỗ trợ và hướng dẫn cho các nhân viên y tế địa phương xác định thứ tự ưu tiên vận chuyển bệnh nhân về các tuyến y tế thích hợp.

- Hướng dẫn thực hiện các can thiệp xử lý vết bỏng (ví dụ: Thay băng, cắt lọc, rạch hoại tử giải phóng chèn ép).

- Hỗ trợ chăm sóc những bệnh nhân trong nhóm cần được chăm sóc giảm nhẹ.

\section{3. Điều phối}

- Nếu được yêu cầu, sẽ hỗ trợ cho lực lượng điều phối hoặc trung tâm điều phối tại các bệnh viện và các trung tâm.

- Góp phần đưa ra quyết định liên quan đến việc chuyển bệnh nhân và phân phối lại bệnh nhân cho các cơ sở y tế.

- Hỗ trợ trung tâm chỉ huy y tế xác định nhu cầu hỗ trợ đội cấp cứu chuyên khoa bỏng.

Sau khi tiếp nhận yêu cầu của cơ quan y tế địa phương bị ảnh hưởng, các đội phản ứng nhanh của quốc gia nên triển khai ngay (lý tưởng nhất là có mặt tại địa phương trong vòng 6 đến 12 giờ). Đội phản ứng nhanh thường sẽ không hỗ trợ trực tiếp tại hiện trường mà tốt nhất nên tập trung hỗ trợ tại các bệnh viện tiếp nhận đầu tiên không có chuyên khoa về bỏng. Cơ chế này đòi hỏi quốc gia phải duy trì đội ngũ chuyên gia bỏng tại các bệnh viện chuyên khoa (những cá nhân không thuộc đội phản ứng nhanh).

Đội phản ứng nhanh lý tưởng phải tự đảm bảo trang thiết bị chuyên dụng, vật tư tiêu hao, phương tiện liên lạc, thức ăn, nước uống và đảm bảo chỗ ở trong thời gian tối 
thiểu 3 ngày đảm nhiệm các nhiệm vụ. Nếu điều kiện cho phép, đội phản ứng nhanh có thể duy trì hoạt động lâu hơn để hỗ trợ trực tiếp công tác chăm sóc y tế 2,3 .

Thảm họa cháy nổ hoặc bỏng hàng loạt thường ít gây phá hủy hoàn toàn cơ sở hạ tầng tại địa phương, do đó thường không cần đến các lều lớn và lượng lớn thiết bị hậu cần, thay vào đó, các đội phản ứng nhanh phải sử dụng trang thiết bị nhẹ và cơ động để có thể khai nhanh chóng. Việc đảm bảo thức ăn, nước uống và chỗ ở cho các đội phản ứng nhanh có thể tận dụng các điều kiện sã̃n có còn lại tại địa phương nếu cho phép. Nên có cơ chế tự chủ về tài chính cho phép các đội phản ứng nhanh thanh toán được các khoản chi phí tại chỗ, tránh trở thành gánh nặng cho chính quyền địa phương 2.
Việc thành lập, đào tạo các đội phản ứng nhanh cần được các quốc gia quan tâm phát triển. Nếu một quốc gia có ít bác sĩ chuyên khoa bỏng, hoặc muốn giữ lại những người này tại các trung tâm điều phối quốc gia, thì các thành viên đội phản ứng nhanh có thể được huy động từ các quốc gia xung quanh. Các đội này cần tuân thủ các tiêu chuẩn quốc tế về đội cấp cứu và tự túc về mọi mặt đảm bảo được tối thiểu hai tuần.

Thành phần biên chế của đội phản ứng nhanh bao gồm 05 thành viên, trong đó có 1 bác sỹ đội trưởng, 1 bác sỹ chuyên ngành bỏng, 1 bác sỹ gây mê hồi sức, 1 điều dưỡng chuyên ngành bỏng và 1 nhân viên hậu cần có kỹ năng cần thiết như sau [1], [3].

Bảng 1. Biên chế của đội phản ứng nhanh 1

\begin{tabular}{|l|c|l|}
\hline \multicolumn{1}{|c|}{ Thành phần } & Số lượng & \multicolumn{1}{c|}{ Kỹ năng cần thiết } \\
\hline Đội trưởng & 1 & Kinh nghiệm đáp ứng khẩn cấp \\
\hline Bác sỹ chuyên ngành bỏng & 1 & $\begin{array}{l}\text { Kinh nghiệm tối thiểu } 5 \text { năm trong lĩnh vực chăm sóc tổn } \\
\text { thương bỏng trong nhiều bối cảnh khác nhau }\end{array}$ \\
\hline $\begin{array}{l}\text { Bác sĩ gây mê có kinh } \\
\text { nghiệm về bỏng }\end{array}$ & 1 & $\begin{array}{l}\text { Kinh nghiệm tối thiểu } 5 \text { năm trong lĩnh vực chăm sóc tổn } \\
\text { thương bỏng trong nhiều bối cảnh khác nhau }\end{array}$ \\
\hline $\begin{array}{l}\text { Điều dưỡng có kinh nghiệm } \\
\text { về bỏng }\end{array}$ & 1 & $\begin{array}{l}\text { Kinh nghiệm tối thiểu } 5 \text { năm trong lĩnh vực chăm sóc tổn } \\
\text { thương bỏng trong nhiều bối cảnh khác nhau }\end{array}$ \\
\hline Nhân viên hậu cần & 1 & $\begin{array}{l}\text { Có kiến thức cơ bản về vệ sinh nguồn nước, kinh nghiệm } \\
\text { quản lý chất thải }\end{array}$ \\
\hline
\end{tabular}

\section{2. Độl CẤP CỨU CHUYÊN KHOA BỎNG (BST)}

Đội chuyên khoa bỏng có quy mô lớn hơn đội phả ứng nhanh, đòi hỏi có nhiều kinh nghiệm về bỏng và các lĩnh vực khác. Dù là các đội trong nước hay quốc tế, đội cấp cứu chuyên khoa đều có các vai trò như sau 1:
- Hỗ trợ quá trình chăm sóc lâm sàng bệnh nhân bỏng.

- Cung cấp chuyên gia có kinh nghiệm để hỗ trợ, tư vấn và hướng dẫn cho y tế địa phương.

- Hỗ trợ tăng cường năng lực cấp cứu điều trị bỏng cho y tế địa phương. 
- Cung cấp kiến thức chuyên môn, chuyên gia, đặc biệt về phục hồi chức năng và kế hoạch điều trị dài hạn cho bệnh nhân.

Các đội cấp cứu chuyên khoa dự kiến sẽ triển khai theo yêu cầu của y tế địa phương hoặc trung tâm điều hành khẩn cấp y tế sau các hoạt động đánh giá ban đầu của đội phản ứng nhanh. Các đội cấp cứu chuyên gia của quốc tế không có khả năng đến quốc gia có thảm họa bỏng sớm trong thời gian vài ngày nhưng có khả năng triển khai các hoạt động độc lập trong thời gian tối thiểu 6 tuần. Đội cấp cứu chuyên khoa cần đảm bảo đủ tiêu chuẩn tối thiểu của đội cấp cứu, tự đảm bảo cho hoạt động độc lập ít nhất trong 2 tuần trước khi được cung cấp bổ sung.

Hai loại hình đội phản ứng nhanh và đội cấp cứu chuyên khoa không cần thiết triển khai riêng cơ sở vật chất tại thực địa vì các đội có nhiều khả năng sẽ ở cùng một cơ sở hiện có.

Các đội cấp cứu chuyên khoa ít có khả năng được triển khai xuyên quốc gia hơn đội phản ứng nhanh vì khó thực hiện (đặc biệt là đối với các đợt triển khai dài) và tốt nhất là nên chia sẻ giữa nhiều quốc gia trong khu vực - được thành lập từ một quốc gia lớn hơn và/hoặc từ sự đóng góp các chuyên gia và nguồn lực từ các quốc gia lân cận trong khu vực 3, 4 .

Vai trò chính của đội cấp cứu chuyên khoa là nâng cao năng lực chuyên sâu cho cơ sở y tế hiện có. Sẽ tốt hơn nếu sử dụng đội ngũ nhân viên y tế có trình độ chuyên môn tại ở nơi làm việc hiện tại, nơi cư trú thân thuộc của họ hơn là phân phối lại nhân sự để hỗ trợ các cơ sở khác. Việc phân bổ nguồn lực nên được xác định theo từng trường hợp cụ thể, phụ thuộc vào bối cảnh và nguồn lực của địa phương, sự sẵn sàng của đội cấp cứu và loại hình thảm họa 5 .
Về biên chế, đội cấp cứu chuyên khoa bỏng tối thiểu gồm 14 người. Trong đó có 01 đội trưởng là người có kinh nghiệm trong xử lý thảm họa, điều phối đáp ứng khẩn cấp về y tế, 02 bác sỹ chuyên khoa bỏng có kinh nghiệm > 5 năm chuyên ngành, 02 bác sỹ gây mê có kinh nghiệm về bỏng và chấn thương, 05 điều dưỡng có kinh nghiệm về bỏng, nhi khoa, 02 kỹ thuật viên phục hồi chức năng đã được đào tạo về phục hồi chức năng trong bỏng, 01 nhân viên hậu cần và 01 nhân viên về dược và trang bị 1 .

Cùng với các đội phản ứng nhanh, đội cấp cứu chuyên khoa cần đăng ký hoạt động có thời hạn với chính quyền địa phương ở quốc gia bị ảnh hưởng và được trung tâm chỉ huy y tế giao nhiệm vụ hỗ trợ các cơ sở liên quan và các đội y tế địa phương.

Thời gian triển khai đội cấp cứu chuyên khoa được khuyến cáo tối thiểu là 6 tuần nhằm đảm bảo điều trị các trường hợp bỏng phức tạp và thời gian điều trị nội trú kéo dài. Nhân viên có thể được luân chuyển trong các nhóm chuyên môn (như được thực hiện trong các đội cấp cứu khác), nhưng tốt nhất là không thường xuyên và việc luân chuyển này phải được thực hiện một cách cẩn thận 7.

Các đội cấp cứu chuyên khoa cần hỗ trợ các phương án đảm bảo việc bàn giao bệnh nhân được diễn ra suôn sẻ và được theo dõi chặt chẽ; triển khai công tác đào tạo và cố vấn cho các lực lượng y tế địa phương.

Các đội phản ứng nhanh và đội cấp cứu chuyên khoa phải đảm bảo báo cáo kết quả công tác hàng tuần cho các cơ quan có liên quan trong suốt quá trình triển khai và báo cáo kết quả tổng kết khi kết thúc nhiệm vụ 8. 
Bảng 2. Biên chế của đội chuyên khoa Bỏng 1

\begin{tabular}{|c|c|c|c|}
\hline Chức năng & Kinh nghiệm tối thiểu/Kỹ năng cốt lõi & $\begin{array}{l}\text { Số } \\
\text { lượng }\end{array}$ & Kinh nghiệm mong muốn \\
\hline Đội trưởng & $\begin{array}{l}\text { Có kinh nghiệm làm việc trong điều phối } \\
\text { đáp ứng khẩn cấp về y tế. }\end{array}$ & 1 & Kinh nghiệm trong xử lý thảm họa. \\
\hline $\begin{array}{l}\text { Bác sĩ chuyên } \\
\text { ngành bỏng }\end{array}$ & > 5 năm kinh nghiệm về bỏng, chấn thương. & 2 & $\begin{array}{l}\text { Kinh nghiệm về chấn thương, thảm } \\
\text { họa bỏng hoặc thương tích hàng } \\
\text { loạt }\end{array}$ \\
\hline Gây mê & > 5 năm kinh nghiệm về bỏng và hồi sức. & 2 & $\begin{array}{l}\text { Kinh nghiêm hoăc được huấn luyện } \\
\text { trong các hoàn cảnh khác nhau. }\end{array}$ \\
\hline Điều dưỡng & $\begin{array}{l}\text { - Kinh nghiêm về bỏng, } 2 \text { - } 5 \text { năm kinh } \\
\text { nghiệm về nhi khoa. } \\
\text { - Kinh nghiệm về thay băng bỏng, hấp } \\
\text { sấy tiệt trùng, điều dưỡng phòng mổ và } \\
1 \text { - } 2 \text { ngươơi có kinh nghiệm tổ chức } \\
\text { phòng mồ. }\end{array}$ & 5 & $\begin{array}{l}\text { Được đào tạo về bỏng, tốt hơn nếu } \\
\text { đã trải qua các tình huống khác } \\
\text { nhau. }\end{array}$ \\
\hline $\begin{array}{l}\text { Phục hồi chức } \\
\text { năng }\end{array}$ & $\begin{array}{l}\text { > } 3 \text { năm kinh nghiệm về bỏng bao gồm } \\
\text { nẹp cố định và chăm sóc hô hấp. }\end{array}$ & 2 & \\
\hline Dược, trang bị & Để quản lý vật tư tiêu hao và thuốc. & 1 & $\begin{array}{l}\text { Kinh nghiệm triển khai y tế khẩn } \\
\text { cấp, quản lý kho y tế, v.v... đặc biệt } \\
\text { trong bỏng. }\end{array}$ \\
\hline Hậu cần & & 1 & $\begin{array}{l}\text { Kinh nghiệm triển khai trong tình } \\
\text { huống khẩn cấp, tự đảm bảo hậu } \\
\text { cần, hỗ trợ điện, nước. }\end{array}$ \\
\hline
\end{tabular}

3. VAI TRÒ CỦA Độl CẤP CỨU BỎNG TRONG THẢM HỌA HẠT NHÂN, SINH HỌC, HÓA HOC

Đội phản ứng nhanh và đội cấp cứu chuyên khoa phải có khả năng hỗ trợ cấp cứu và điều trị cho bệnh nhân bỏng do sự cố hóa chất, sinh học hoặc bức xạ hạt nhân (CBRN). Tuy nhiên, họ không được kỳ vọng sẽ điều trị bệnh nhân ở 'Vùng nóng'. Các nguyên tắc chung về cấp cứu, điều trị bỏng do các thảm họa này về cơ bản cũng như bỏng do nhiệt. Đội phản ứng nhanh có thể cung cấp cơ số điều trị bỏng cho những bệnh nhân loại này (ví dụ: Thuốc giảm đau, Oresol, dịch truyền và băng kháng sinh).

Các thành viên của đội cấp cứu cần có nhận thức tốt và được đào tạo cơ bản về thảm họa CBRN nhưng không yêu cầu đào tạo trình độ chuyên sâu cao hơn. Nhưng phải có kiến thức cụ thể về bỏng hóa chất, bỏng nhiệt do sự cố hạt nhân, bỏng bức xạ 3 .

\section{CÔNG TÁC ĐÀO TẠO, HUẤN LUYỆN ĐộI CẤP CỨU}

Tất cả thành viên đội phản ứng nhanh và đội cấp cứu chuyên khoa phải hoàn thành khóa đào tạo của đội cấp cứu nói chung và đào tạo về an toàn an ninh (có thể tổ chức khóa đào tạo riêng) trước khi đủ điều kiện tham gia đội. Đặc biệt, tất cả các thành viên phải hoàn thành khóa đào tạo tập trung vào việc đảm bảo khả năng chăm sóc bệnh nhân trong tất cả các tình huống, bao gồm cả ở những nợ hạn chế 
về nguồn lực cũng như được đào tạo kỹ năng hoạt động nhóm 5.

Nội dung đào tạo cơ bản cho đội phản ứng nhanh và đội cấp cứu chuyên khoa bao gồm:

- Đánh giá, phối hợp và chỉ đạo trong thảm họa/bỏng hàng loạt

- Chăm sóc lâm sàng bao gồm hồi sức, vận chuyển bệnh nhân bỏng an toàn.

- Tổ chức đáp ứng với bỏng hàng loạt.

- Cơ chế phối hợp, vận chuyển bệnh nhân giữa địa phương và trung ương

- Xử trí tình huống nạn nhân gia tăng đột biến.

- Những bài học kinh nghiệm trong các thảm họa bỏng.

Đối tượng đào tạo chuyên khoa bỏng là các bác sĩ lâm sàng và các thành viên của hệ thống điều phối địa phương như thành viên trung tâm chỉ huy y tế khẩn cấp. Tất cả thành viên của các đội phải hoàn thành khóa đào tạo chuyên ngành về điều trị bỏng, đặc biệt tập trung vào bỏng hàng loạt, trong khi các trưởng nhóm và bác sĩ lâm sàng phải được đào tạo về điều phối và xử trí khẩn cấp.

Trên toàn cầu, hiện có các khóa học chung đảm bảo việc đào tạo có thể tiếp cận được trong khu vực và quốc tế, khả thi về mặt kinh tế. Các chuyên gia có nhiều kinh nghiệm về đào tạo và chuyên ngành bỏng được khuyến khích là cố vấn cho các nhóm mới thành lập và hỗ trợ đào tạo với tư cách là giảng viên chuyên nghiệp.

Chương trình đào tạo nên thực hiện theo hướng tiếp cận các module (ví dụ: Các hoạt động dựa trên hội thảo, mô phỏng đóng vai, lên lớp). Bên cạnh đó cũng cần tăng cường các chương trình giáo dục cộng đồng trong việc chăm sóc, sơ cấp cứu nạn nhân bỏng tại hiện trường.
Việc đào tạo cho các đội cấp cứu trong bối cảnh nguồn lực hạn chế phải đáp ứng được các yêu cầu và phù hợp với văn hóa địa phương, phù hợp với loại hình chăm sóc nạn nhân bỏng và được điều chỉnh để đáp ứng các cấp độ từ cơ bản, trung bình đến nâng cao. Các chương trình huấn luyện, công cụ huấn luyện và đào tạo cho các đội cấp cứu có thể được truy cập thông qua các trang web của Tổ chức $Y$ tế Thế giới 5 .

\section{TÀI LIẸU THAM KHẢO}

1. Hughes A, Almeland SK, Leclerc T, et al. Recommendations for burns care in mass casualty incidents: WHO Emergency Medical Teams Technical Working Group on Burns (WHO TWGB) 2017-2020. Burns. 2021; 47(2): 349-370.

2. European Commission. Preparing for mass burn casualty incidents. 2020

3. Kearns RD, Marcozzi DE, Barry N, et al. Disaster Preparedness and Response for the Burn Mass Casualty Incident in the Twenty-first Century. Clin Plast Surg. 2017; 44(3): 441-449.

4. Norton I, von Schreeb J, Aitken P, et al. Classification and Minimum Standards for Foreign Medical Teams in Sudden Onset Disasters. 2013.

5. World Health Organization (WHO). Classification and Minimum Standards for Foreign Medical Teams in Sudden Onset Disasters. Geneva: WHO, 2013.

6. Amat Camacho N, Hughes A, Burkle FM, et al. Education and training of emergency medical teams: Recommendations for a global operational learning framework. PLoS Curr. 2016; 8.

7. World Health Organization (WHO). Understanding the Global EMT Classification Process.

https://extranet.who.int/emt/page/understandin g-global-emt-classification-process.

8. Jafar AJ, Norton I, Lecky F, Redmond AD. A literature review of medical record keeping by foreign medical teams in sudden-onset disasters. Prehosp Disaster Med. 2015; 30(2): 216-222. 